\title{
The effect of malnutrition on patients undergoing elective joint arthroplasty.
}

\author{
Ronald Huang, MD \\ Rothman Institute at Thomas Jefferson University \\ Max Greenky, BS \\ Rothman Institute at Thomas Jefferson University \\ Glenn J. Kerr, MD \\ Rothman Institute at Thomas Jefferson University \\ Mathew S. Austin, MD \\ Rothman Institute at Thomas Jefferson University \\ Javad Parvizi, MD, FRCS \\ Rothman Institute at Thomas Jefferson University \\ Follow this and additional works at: https://jdc.jefferson.edu/rothman_institute \\ Part of the Orthopedics Commons \\ Let us know how access to this document benefits you
}

\section{Recommended Citation}

Huang, MD, Ronald; Greenky, BS, Max; Kerr, MD, Glenn J.; Austin, MD, Mathew S.; and Parvizi, MD, FRCS, Javad, "The effect of malnutrition on patients undergoing elective joint arthroplasty." (2013). Rothman Institute Faculty Papers. Paper 51.

https://jdc.jefferson.edu/rothman_institute/51

This Article is brought to you for free and open access by the Jefferson Digital Commons. The Jefferson Digital Commons is a service of Thomas Jefferson University's Center for Teaching and Learning (CTL). The Commons is a showcase for Jefferson books and journals, peer-reviewed scholarly publications, unique historical collections from the University archives, and teaching tools. The Jefferson Digital Commons allows researchers and interested readers anywhere in the world to learn about and keep up to date with Jefferson scholarship. This article has been accepted for inclusion in Rothman Institute Faculty Papers by an authorized administrator of the Jefferson Digital Commons. For more information, please contact: JeffersonDigitalCommons@jefferson.edu. 
As submitted:

The Journal of arthroplasty.

And later published as:

The Effect of Malnutrition on Patients Undergoing Elective Joint Arthroplasty

Volume 28, Issue 8 Supplement, September 2013, pages: 21-24.

DOI: $10.1016 / j . a r t h .2013 .05 .038$

Ronald Huang MD

Max Greenky BS

Glen J. Kerr MD

Matthew S. Austin MD

Javad Parvizi MD, FRCS

The Rothman Institute at Thomas Jefferson University, Philadelphia, PA 19107 


\begin{abstract}
:
Malnutrition has been linked to serious complications in patients undergoing elective total joint arthroplasty (TJA). This study prospectively evaluated 2,161 patients undergoing elective TJA for malnutrition as defined by either an abnormal serum albumin or transferrin. The overall incidence of malnutrition was $8.5 \%(184$ of 2,161) and the rate of overall complications in the malnourished group was $12 \%$ as compared to $2.9 \%$ in patients with normal parameters (P b 0.0001). Malnutrition predicted serious complications involving hematoma formation, infection, renal and cardiac complications. Obesity, defined by a body mass index (BMI) of 30 $\mathrm{kg} / \mathrm{m} 2$ was present in $42.9 \%$ of malnourished patients with a significantly higher complication rate in this cohort. Malnutrition remains prevalent in patients N55 years-old undergoing TJA and is associated with a significant increase in post-operative complications.
\end{abstract}




\section{Introduction:}

The association between malnutrition and adverse outcomes following major surgical procedures has been documented for over 50 years [1-4]. In the orthopedic literature there are multiple studies demonstrating poor outcomes in malnourished patients undergoing elective joint arthroplasty, hip fractures and amputations [5-10]. The influence of malnutrition on the incidence of superficial or deep infection and wound related problems has also been the focus of many studies [11-13]. In one study evaluating total knee revisions with wound healing issues, over $88 \%$ of wound complications involved malnourished patients [14]. Nevertheless, the overall rate of complications associated with malnutrition in total joint arthroplasty (TJA) has not been identified.

Clinical signs of malnutrition often become apparent only in extreme cases. Laboratory values which indicate nutritional insufficiency may be used as a screening tool for preoperative nutritional status $[2,6,9,18]$. The determination of the most appropriate tests in specific patients is poorly defined [19-26]. Serum albumin, total lymphocyte count and serum transferrin are commonly used to define nutritional status. The threshold defining malnutrition and the predictive value of using these markers have been questioned [13,19,20,22].

We sought to more clearly define the effect of malnutrition on the results of elective TJA by prospectively collecting nutritional markers in a large consecutive cohort of patients undergoing primary and revision joint arthroplasty. The purpose of our study was: (1) to compare the overall rate of complications in malnourished patients and non-malnourished patients, (2) to examine the incidence of malnourishment and complications in obese patients undergoing TJA, (3) to identify predictive values for nutritional markers, and (4) to develop an effective methodology to identify patients at risk for complications due to malnutrition. 


\section{Materials and Methods:}

\section{Demographic Data}

Following institutional review board approval, the prospective collection of nutrition markers began in April 2010 in all patients undergoing elective total joint arthroplasty at our institution. Patients that underwent total hip arthroplasty (THA) for hip fracture or revision TJA for urgent issues such as periprosthetic joint infection or trauma were excluded. Between April 2010 and May 2011 2,161 consecutive patients underwent elective primary and revision TJA; 1,673 patients underwent primary unilateral TJA, 238 patients underwent simultaneous bilateral primary TJA, 247 patients underwent revision TJA, and 3 patients underwent simultaneous bilateral revision TJA.

Unilateral or bilateral primary TJA was performed in 1,911 patients. Primary total knee arthroplasty (TKA) was performed in 1,001 patients and primary THA was performed in 910 patients. Revision TJA was performed in 250 patients of which 133 patients underwent revision TKA and 117 patients underwent revision THA. There were 980 males with a mean age of 62.8 (range, 18-92 years old) and 1,181 females with a mean age of 65.4 (range, 19-96 years old).

\section{Perioperative Data}

Nutritional markers were obtained at our institution during preadmission testing, 2-4 weeks prior to surgery. Standardized testing included complete blood count, paneled electrolytes, and coagulation studies. In addition to routine preoperative tests, patients were also evaluated for serum transferrin and albumin levels. All testing was performed by the same laboratory with standardized reference values for each test. Patients were categorized as malnourished if either serum albumin levels were less than or equal to $3.5 \mathrm{mg} / \mathrm{dl}[5,8]$ or when serum transferrin levels were $b 200 \mathrm{mg} / \mathrm{dl}$ [23]. The WHO classification for obesity was used to classify the patient's BMI 
into categories [27]. Demographic data is presented in Table 1. No cases were canceled or rescheduled due to abnormal nutrition labs.

TJA was performed under regional anesthesia for all patients, unless contraindicated. All TJA surgeries were performed by 1 of 6 high-volume arthroplasty surgeons. All procedures were performed in a laminar flow operating room and all patients were given standard antibiotic prophylaxis administered according to Surgical Care Improvement Project (SCIP) guidelines [28]. All TKA procedures were performed using a medial parapatellar approach with a tourniquet and cement fixation for all components. All THA procedures were performed supine, either utilizing a modified anterolateral gluteus medius-splitting approach or a modified direct anterior approach. Cementless femoral and acetabular components were used in all primary THAs and in most revision THAs.

The institutional database was queried, using hospital and surgeon billing codes, to identify all patients who developed complications and wound healing problems. Complications were defined as in-hospital complications by system based on ICD-9 codes and postoperative complications requiring readmission or reoperation within 12 months of surgery. Specifically, International Classification of Diseases (ICD-9) and Current Procedural Terminology (CPT) codes were used. All cases with identified complications were further investigated through review of hospital charts and clinic medical records.

\section{Statistical Analysis}

Analysis was done to evaluate risk factors for developing postoperative complications and wound healing problems. Univariate analysis was performed, using chi-squared analyses to identify the effect of categorical variables on outcome and Student's $t$ test for continuous variables. Demographic variables that produced a P value of b0.05 are summarized in Table 1. 
Complication data is summarized in Table 2. Multivariate backwards stepwise logistic regression analyses were also performed for each complication to identify independent predictors. All statistical analysis was done using SPSS software (Version 20.0; PASW, Chicago, IL, USA).

\section{Results:}

The overall incidence of malnutrition, defined as either low albumin or transferrin values, in our study population was $8.5 \%$ (184 of 2,161). Malnourished patients had higher Charlson Index (2.32 vs 1.99; $\mathrm{P}=0.001)$ and had longer length of stay (4.5 vs 2.8 days; $\mathrm{P}$ b 0.001). Additionally, although not statistically significant, a larger proportion of malnourished patients were males $(\mathrm{P}=0.052)$ (Table 1$)$. Of the malnourished patients, $22.3 \% \%$ of had a low albumin and normal transferrin, $72.8 \%$ of patients had a normal albumin and low transferrin, and $4.9 \%$ of patients had abnormal albumin and transferrin. In patients defined as malnourished, the overall complication rate was $12.0 \%$ (22 of 184 cases) compared to $2.9 \%$ (58 of 1,977 cases) in patients with a normal albumin and transferrin ( $\mathrm{P}$ b 0.0001).

Age was not a significant factor in developing malnutrition but the incidence increased steadily through age 70 (Fig.). The overall incidence of complications was 3.7\% (80/2161 patients). The incidence of complications was also significantly higher in malnourished obese patients at $10.4 \%$ ( 8 of 77 cases) compared to $3.2 \%$ (30 of 946 cases) in obese patients with normal nutritional values ( $\mathrm{P}$ b 0.001$)$. Obesity was noted in $42.9 \%$ of malnourished patients. Malnutrition was much more common in the revision setting compared to primary total joint arthroplasty ( $\mathrm{P}$ b 0.001). Lengths of stay exceeding 3 days were more prevalent in patients with malnutrition as compared to patients with normal nutrition ( $\mathrm{P} \mathrm{b} \mathrm{0.001).}$ 
Renal complications were the most common complication experienced by malnourished patients and occurred at significantly higher rates than in non-malnourished patients. The overall rates of postoperative complications were quite low in this cohort but on univariate analyses, malnutrition was significantly associated with an increased risk of all complications ( $\mathrm{P} \mathrm{b} \mathrm{0.001),}$ as well as cardiovascular $(\mathrm{P}=0.001)$, neurovascular ( $\mathrm{P} \mathrm{b} 0.001)$, renal $(\mathrm{P} \mathrm{b} 0.001)$, the need for irrigation and debridement $(\mathrm{P}=0.002)$, postoperative hematoma/seroma formation $(\mathrm{P} \mathrm{b} \mathrm{0.001})$, and acute infection within 3 months of surgery ( $\mathrm{P} \mathrm{b} \mathrm{0.001)} \mathrm{(Table} \mathrm{2).} \mathrm{There} \mathrm{was} \mathrm{an} \mathrm{increased} \mathrm{rate}$ of periprosthetic joint infection (PJI) and development of a hematoma or seroma ( $\mathrm{P} \mathrm{b}$ 0.001) in malnourished patients. On multivariate analysis, accounting for the confounding variables of revision vs. primary procedures, comorbid conditions, surgical factors and demographics, malnutrition was an independent predictor of neurovascular complications, renal complications, postoperative hematoma and seroma formation, and overall complication rate (Table 3). When patients undergoing primary and revision TJA were analyzed separately, multivariate analysis found malnutrition to be an independent predictor of renal, neurovascular, postoperative hematoma/seroma, and overall complications.

\section{Discussion:}

The role of nutrition in wound healing and complications in orthopedic surgery has been identified in previous studies [6-11,14,29]. Despite this association, application of laboratory screening for malnutrition remains poorly defined and cumbersome for surgeons. The diagnosis of malnutrition may not be obvious in certain demographics of patients. Patients at risk for malnutrition classically have been identified based on low body mass index. Over half of the patients enrolled in this study were obese and obese patients represented nearly half of the 
malnourished cohort. This study provides current and reliable information regarding the risks for malnutrition by age, BMI and the distribution of expected complications. We established threshold values for screening using two readily available serum tests.

Through this cohort of patients we can more readily define the demographics of patients who are at risk for malnutrition in joint arthroplasty. The vast majority of patients under the age of 55 had normal nutritional labs $98.3 \%$ (2125/2161). Malnutrition peaked in the 6th and $7^{\text {th }}$ decades and declined beyond the age of 70 . Healthier patients had greater longevity and were less likely to have malnutrition. The distribution of malnutrition did not differ by gender. As expected, there was a greater incidence of malnutrition in patients undergoing revision surgery. Malnourished patients also had significantly longer hospital stays which is consistent with historical data $[6,8,13,18,30]$. The overall rate of infection lower in this study compared to historical reports of malnourished patients $[6-8,18]$.

In addition to poorer nutrition, patients undergoing revision TJA have generally more comorbid conditions, confounding variables that may also lead to increased postoperative complications. However, in our multivariate logistic regression model, we accounted for revision surgery and comorbid conditions as confounding variables and found malnutrition to be an independent predictor of postoperative complications. Furthermore, in the population of only patients undergoing primary TJA, malnutrition was still an independent predictor of postoperative complications.

Malnutrition should be considered in obese patients who are a growing demographic in developed countries and with a proportional increase in TJA $[15,17,31,32]$. Obese patients who have a high caloric intake of nutritionally deficient foods may also be malnournished [15- 
17]. The complication rate in malnourished obese patients was over $10 \%$, which was three times higher than in obese patients with normal nutrition. Obesity in patients undergoing elective TJA is increasing and our results point to the importance of considering nutritional deficiency in this population [33]. The use of nutritional screening in obese patients may not be entirely intuitive but may be an important parameter to assess in this challenging population.

Initial investigations by Jensen et al., performed on patients undergoing elective and traumatic orthopedic procedures, demonstrated a rate of malnutrition of $29 \%$ in patients undergoing hip arthroplasty and up to $52 \%$ in trauma patients [6]. They employed a battery of 7 tests including albumin, TLC, transferrin, triceps skin fold, skin antigen testing and arm circumference measurements. Complications and wound issues were correlated with malnutrition in this study. The complexity and logistics of employing each of these tests in large groups of patients have resulted in a narrowed laboratory battery to screen for malnutrition. In 1991 Greene et al. published on the role of albumin and total lymphocyte count in predicting wound drainage and deep infection [8]. Of the 217 patients' examined, 27\% met the criteria for malnourishment and the study noted a predictive value of $100 \%$ of major complication when both tests were abnormal ( 2 or 217 patients). This article stressed the importance of the total lymphocyte count in predicting malnutrition and complications. Other contemporary literature disputes the utility of the TLC when stratified into varying categories there was no correlation with anthropomorphic testing or other serum markers for malnutrition [6,20,22].

There is direct support for the use of serum albumin and transferrin in screening for malnutrition and this combination was adopted for this study [4,13]. A threshold value of 3.5 $\mathrm{mg} / \mathrm{dl}$ was used for serum albumin and $200 \mathrm{mg} / \mathrm{dl}$ for serum transferrin $[5,13,23,34]$. Although 
the threshold value for serum albumin has remained constant in most studies, the threshold values for transferrin differ ranging from 200 to $226 \mathrm{mg} / \mathrm{dL}$ [23,35].

There is no orthopaedic literature that strongly supports using either transferrin, albumin, or both to define malnutrition. However, multiple studies by Greene et al, Mullen et al, and Gherini et al. have shown that both low albumin and transferrin levels are independently associated with increased rates of some postoperative complications $[4,8,13]$. Furthermore, defining malnutrition as either low albumin or low transferrin allowed an increased sensitivity to identify malnourished patients, possibly at the expensive of some specificity.

A simplified approach to the nutritional evaluation of candidates for elective arthroplasty can now be applied, with two serum tests, in patients greater than age 55. If either are abnormal, then delay of elective surgery should be considered until the patient has undergone nutritional optimization.

\section{Conclusion:}

Malnutrition continues to be prevalent in patients undergoing total joint arthroplasty and leads to a significant increase in postoperative complications. In particular patients with obesity and malnutrition are also at increased risk of complications. Serum albumin and transferrin are useful pre-operative screening labs and are recommended for patients over the age of 55 . The influence of correction of nutritional parameters on outcome following TJA will be determined in a subsequent study. 


\section{References:}

1. Cannon PR, Wissler RW, Woolridge RL, et al. The relationship of protein deficiency to surgical infection. Ann Surg 1944;120(4):514.

2. Werner M, Cohnen G. Changes in serum proteins in the immediate postoperative period. Clin Sci 1969;36(2):173.

3. Law DK, Dudrick SJ, Abdou NI. The effects of protein calorie malnutrition on immune competence of the surgical patient. Surg Gynecol Obstet 1974;139(2):257.

4. Mullen JL, Gertner MH, Buzby GP, et al. Implications of malnutrition in the surgical patient. Arch Surg 1979;114(2):121.

5. Dreblow DM, Anderson CF, Moxness K. Nutritional assessment of orthopedic patients. Mayo Clinic proceedings Mayo Clinic 1981;56(1):51.

6. Jensen JE, Jensen TG, Smith TK, et al. Nutrition in orthopaedic surgery. J Bone Joint Surg Am 1982;64(9):1263.

7. Smith TK. Prevention of complications in orthopedic surgery secondary to nutritional depletion. Clin Orthop Relat Res 1987;222:91.

8. Greene KA, Wilde AH, Stulberg BN. Preoperative nutritional status of total joint patients. Relationship to postoperative wound complications. J Arthroplasty 1991;6(4):321.

9. Dickhaut SC, DeLee JC, Page CP. Nutritional status: importance in predicting woundhealing after amputation. J Bone Joint Surg Am 1984;66(1):71.

10. Eneroth M, Apelqvist J, Larsson J, et al. Improved wound healing in transtibial amputees receiving supplementary nutrition. Int Orthop 1997;21(2):104. 
11. Jaberi FM, Parvizi J, Haytmanek CT, et al. Procrastination of wound drainage and malnutrition affect the outcome of joint arthroplasty. Clin Orthop Relat Res 2008;466(6):1368.

12. Font-Vizcarra L, Lozano L, Rios J, et al. Preoperative nutritional status and postoperative infection in total knee replacements: a prospective study of 213 patients. Int J Artif Organs 2011;34(9):876.

13. Gherini S, Vaughn BK, Lombardi Jr AV, et al. Delayed wound healing and nutritional deficiencies after total hip arthroplasty. Clin Orthop Relat Res 1993;293:188.

14. Ries MD. Skin necrosis after total knee arthroplasty. J Arthroplasty 2002;17(4 Suppl $1): 74$.

15. Via M. The malnutrition of obesity: micronutrient deficiencies that promote diabetes. ISRN Endocrinol 2012;2012:103472.

16. Swinburn BA, Sacks G, Hall KD, et al. The global obesity pandemic: shaped by global drivers and local environments. Lancet 2011;378(9793):804.

17. Kaidar-Person BP O, Szomstein S, Rosen-thal RJ. Nutritional deficiencies in morbidly obese patients: a new form of malnutrition? Part A: vitamins. Obes Surg 2008;18:870.

18. Del Savio GC, Zelicof SB, Wexler LM, et al. Preoperative nutritional status and outcome of elective total hip replacement. Clin Orthop Relat Res 1996;326:153.

19. Goodwin JS, Garry PJ. Lack of correlation between indices of nutritional status and immunologic function in elderly humans. J Gerontol 1988;43(2):M46.

20. Kuzuya M, Kanda S, Koike T, et al. Lack of correlation between total lymphocyte count and nutritional status in the elderly. Clin Nutr 2005;24(3):427. 
21. O'Daly BJ, Walsh JC, Quinlan JF, et al. Serum albumin and total lymphocyte count as predictors of outcome in hip fractures. Clin Nutr 2010;29(1):89.

22. Izaks GJ, Remarque EJ, Becker SV, et al. Lymphocyte count and mortality risk in older persons. The Leiden 85-Plus Study. J Am Geriatr Soc 2003;51(10):1461.

23. Thean K, Yo SL, Nambiar R, et al. The use of serum transferrin in the evaluation of protein-calorie malnutrition in cancer patients. Ann Acad Med Singapore 1988;17(1):124.

24. Bouillanne O, Morineau G, Dupont C, et al. Geriatric Nutritional Risk Index: a new index for evaluating at-risk elderly medical patients. Am J Clin Nutr 2005;82(4): 777.

25. Cereda E, Vanotti A. The new Geriatric Nutritional Risk Index is a good predictor of muscle dysfunction in institutionalized older patients. Clin Nutr 2007;26(1):78.

26. Poulia KA, Yannakoulia M, Karageorgou D, et al. Evaluation of the efficacy of six nutritional screening tools to predict malnutrition in the elderly. Clin Nutr 2012;31(3):378.

27. Obesity: preventing and managing the global epidemic. Report of a WHO consultation. World Health Organization technical report series. 2000;894:i-xii, 1-253.

28. Bratzler DW, Hunt DR. The surgical infection prevention and surgical care improvement projects: national initiatives to improve outcomes for patients having surgery. Clin infect Dis: An official Public Infect Dis Soc Am 2006;43(3):322.

29. Garcia Duque S, Perez Segura G, Sanavia Moran E, et al. Nutritional control in orthopedic surgery patients. Nutricion hospitalaria: organo oficial de la Sociedad Espanola de Nutricion Parenteral y Enteral 2008;23(5):493. 
30. Correia MI, Waitzberg DL. The impact of malnutrition on morbidity, mortality, length of hospital stay and costs evaluated through a multivariate model analysis. Clin Nutr 2003;22(3):235.

31. Flegal KM, Carroll MD, Kit BK, et al. Prevalence of obesity and trends in the distribution of body mass index among US adults, 1999-2010. JAMA 2012;307(5):491.

32. Finucane MM, Stevens GA, Cowan MJ, et al. National, regional, and global trends in body-mass index since 1980: systematic analysis of health examination surveys and epidemiological studies with 960 country-years and 9.1 million participants. Lancet 2011;377(9765):557.

33. Bourne R, Mukhi S, Zhu N, et al. Role of obesity on the risk for total hip or knee arthroplasty. Clin Orthop Relat Res 2007;465:185.

34. Reinhardt GF, Myscofski JW, Wilkens DB, et al. Incidence and mortality of hypoalbuminemic patients in hospitalized veterans. JPEN J Parenter Enteral Nutr 1980;4(4):357 .

35. Evans RP, Clyburn TA, Moucha CS, et al. Surgical site infection prevention and control: an emerging paradigm. Instr Course Lect 2011;60:539. 
Figure 1. Incidence of malnutrition by age.

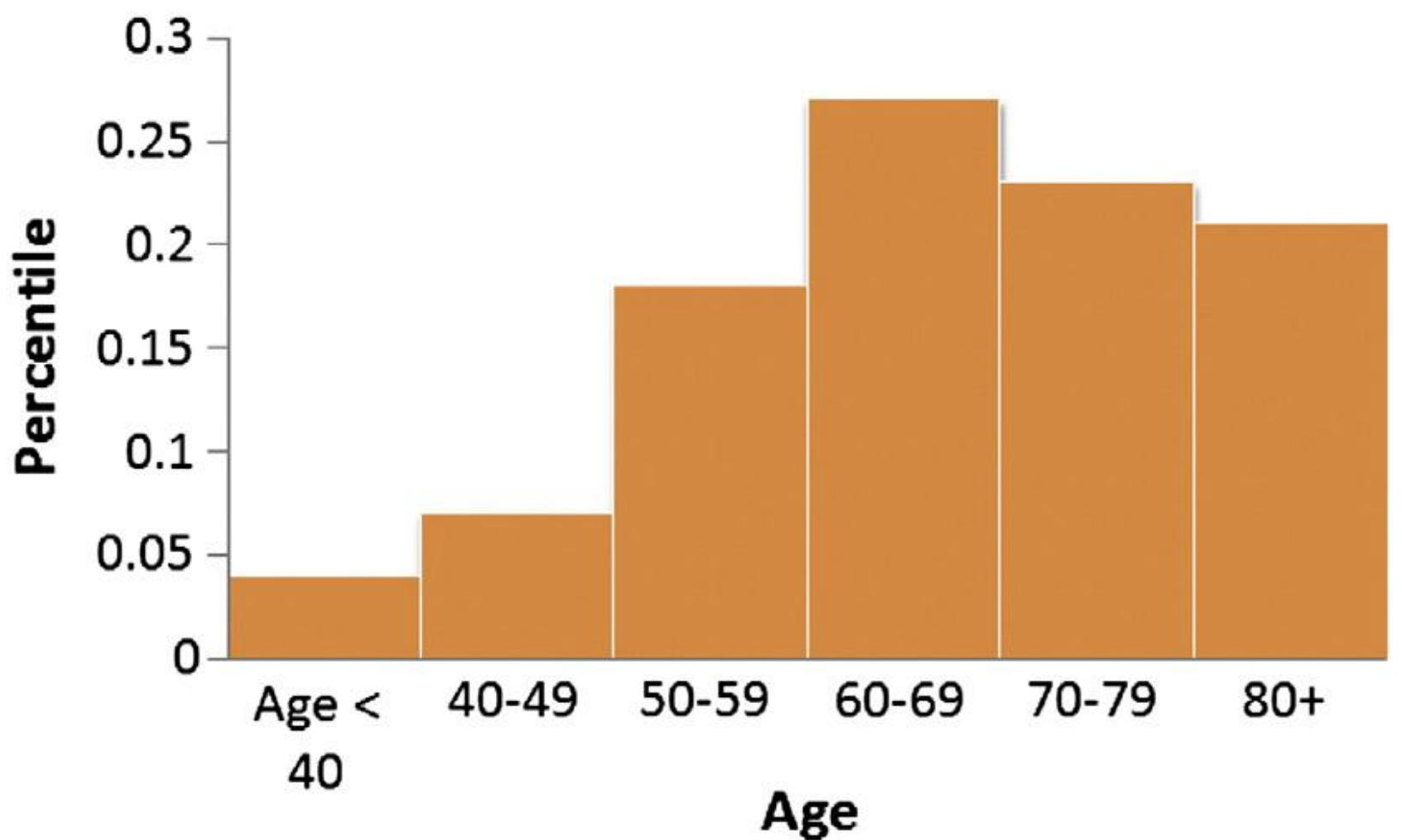


Table 1. Demographics

\begin{tabular}{llll}
\hline & $\begin{array}{c}\text { Malnourished } \\
\text { (Low Albumin or } \\
\text { Transferrin }(\mathrm{n}=184)\end{array}$ & $\begin{array}{c}\text { Normal Transferrin } \\
\text { and Albumin } \\
(\mathrm{n}=1977)\end{array}$ & $P$-value \\
\hline & & & \\
Age $>$ 55 & & & \\
Gender (male/female) & $148 / 184(80.4 \%)$ & $1613 / 1977(81.6 \%)$ & 0.7 \\
BMI <20 & $6 / 184(3.2 \%)$ & $31 / 1977(1.6 \%)$ & 0.07 \\
BMI 20-29.9 & $99 / 184(53.8 \%)$ & $998 / 1977(50.5 \%)$ & 0.4 \\
BMI 30-39.0 & $69 / 184(37.5 \%)$ & $829 / 1977(41.9 \%)$ & 0.3 \\
BMI $>$ 40 & $10 / 184(5.4 \%)$ & $119 / 1977(6.0 \%)$ & 0.9 \\
Primary & $138 / 184(75 \%)$ & $1774 / 1977(89.7 \%)$ & $<0.001$ \\
Revisions & $46 / 184(25 \%)$ & $203 / 1977(10.3 \%)$ & See above \\
Length of stay $>3$ days & $83 / 184(45 \%)$ & $317 / 1977(16 \%)$ & $<0.001$ \\
& & & \\
\hline
\end{tabular}

Table 2. Complications and Nutrition

\begin{tabular}{lccc}
\hline & $\begin{array}{c}\text { Malnourished (Low Albumin } \\
\text { or Transferrin (n=184)) }\end{array}$ & $\begin{array}{c}\text { Normal Transferrin and } \\
\text { Albumin (n=1977) }\end{array}$ & $P$-Value \\
\hline $\begin{array}{l}\text { Cardiovascular } \\
\text { complications }\end{array}$ & $1 / 184(0.5 \%)$ & $0 / 1977(0 \%)$ & 0.001 \\
Neurovascular complications & $5 / 184(2.7 \%)$ & $0 / 1977(0 \%)$ & $<0.001$ \\
Pulmonary complication & $2 / 184(1.1 \%)$ & $6 / 1977(0.3 \%)$ & 0.094 \\
Renal complication & $10 / 184(5.4 \%)$ & $16 / 1977(0.8 \%)$ & $<0.001$ \\
Required I\&D & $5 / 184(2.7 \%)$ & $12 / 1977(0.6 \%)$ & 0.002 \\
Hematoma & $7 / 184(3.8 \%)$ & $13 / 1977(0.7 \%)$ & $<0.001$ \\
DVT & $3 / 184(1.6 \%)$ & $21 / 1977(1.1 \%)$ & 0.482 \\
PE & $2 / 184(1.1 \%)$ & $15 / 1977(0.8 \%)$ & 0.63 \\
Acute Infection within 3 \\
months
\end{tabular}


Table 3. Multivariate Analysis.

\begin{tabular}{|c|c|c|c|c|}
\hline & $\begin{array}{l}\text { Low Albumin or } \\
\text { Transferrin } \\
(\mathrm{n}=184)\end{array}$ & $\begin{array}{l}\text { Normal Transferrin } \\
\text { and Albumin } \\
(\mathrm{n}=1977)\end{array}$ & Odds Ratio & $P$-Value \\
\hline Cardiovascular complication & $1 / 184(0.5 \%)$ & $0 / 1977(0 \%)$ & $\begin{array}{c}16.84 \text { (95\% CI: } 0.46- \\
618.08)\end{array}$ & 0.124 \\
\hline Neurovascular complication & $5 / 184(2.7 \%)$ & $0 / 1977(0 \%)$ & $\begin{array}{c}41.95 \text { (95\% CI: } 3.07- \\
574.07)\end{array}$ & 0.005 \\
\hline Pulmonary complication & $2 / 184(1 / 1 \%)$ & $6 / 1977(0.3 \%)$ & $\begin{array}{c}1.69 \text { (95\% CI: } 0.31- \\
9.21)\end{array}$ & 0.545 \\
\hline Renal complication & $10 / 184(5.4 \%)$ & 16/1977 (0.8\%) & $\begin{array}{c}2.85 \text { (95\% CI: } 1.20- \\
6.77)\end{array}$ & 0.017 \\
\hline Required I\&D & $5 / 184(2.7 \%)$ & $12 / 1977(0.6 \%)$ & $\begin{array}{c}1.81 \text { (95\% CI: } 0.58- \\
5.64)\end{array}$ & 0.306 \\
\hline Hematoma/seroma & $7 / 184(3.8 \%)$ & 13/1977 (0.7\%) & $\begin{array}{c}8.37 \text { (95\% CI: } 1.57- \\
44.66)\end{array}$ & 0.013 \\
\hline DVT & $3 / 184(1.6 \%)$ & 21/1977 (1.1\%) & $\begin{array}{l}1.50 \text { (95\% CI: } 0.42- \\
5.33)\end{array}$ & 0.535 \\
\hline $\mathrm{PE}$ & $2 / 184(1.1 \%)$ & 15/1977 (0.8\%) & $\begin{array}{l}1.22 \text { (95\% CI: } 0.25- \\
5.95)\end{array}$ & 0.807 \\
\hline $\begin{array}{l}\text { Acute infection within } 3 \\
\text { months }\end{array}$ & $5 / 184(2.7 \%)$ & $8 / 1977(0.4 \%)$ & $\begin{array}{c}2.37 \text { (95\% CI: } 0.73- \\
7.76)\end{array}$ & 0.154 \\
\hline Any complication & $22 / 184(12.0 \%)$ & $58 / 1977(2.9 \%)$ & $\begin{array}{c}2.42 \text { (95\% CI: } 1.34- \\
4.39)\end{array}$ & 0.004 \\
\hline
\end{tabular}

